\title{
Hypnotherapy and Regulated Uncovering in the Treatment of Older Survivors of Nazi Persecution
}

\author{
Eli Somer, $\mathrm{PhD}$
}

EDITOR'S INTRODUCTION TO THE CHAPTER: In some ways, the previous case of paranoia also makes a nice contrast with depression. While the paranoids deny that they have a problem (and merely blame others), depressives tend to introject blame and shame from others.

In other ways, dissociative reaction is the opposite of paranoia. The former represses traumatic memories, while the latter indulges in traumatic fantasies and then projects them. If paranoids can be treated without insight, then dissociative reaction may require insight. While paranoids can be treated with supportive therapy, dissociative reaction may require a dramatic process of uncovering. There is no more useful tool in this than hypnotherapy.

I am not certain if the following case of a 58 year old Israeli woman is more depressed or dissociative, but Somer demonstrates the need to prepare the patient for hypnotherapy with appropriate medications as well as with psychotherapy. Furthermore, after the abreaction, the patient must receive additional treatment to deal with uncovered grief.

The debate over whether it is necessary and wise to uncover painful memories in the aged is not resolved, and will continue in this forum. However, if such uncovery is to take place, we should

Eli Somer is affiliated with the R. D. Wolfe Centre for Study of Psychological Stress, University of Haifa, Haifa 31999, Israel.

[Haworth co-indexing entry note]: "Hypnotherapy and Regulated Uncovering in the Treatment of Older Survivors of Nazi Pensecution." Somer, Eli. Co-published simultaneously in the Clinical Gerontologist (The Haworth Press, Inc.) Vol. 14, No. 3, 1994, pp. 47-65; and: Holocaust Survivors' Mental Health (ed: T. L. Brink) The Haworth Press, Inc., 1994, pp. 47-65. Multiple copies of this article/chapter may be purchased from The Haworth Document Delivery Center [1-800-3-HAWORTH; 9:00 am. 5:00 pm. (EST)].

(C) 1994 by The Haworth Press, Inc. All rights reserved. 
follow Somer's guidelines in order to minimize risks to the patient and secure maximum therapeutic outcome.

Survivors of the Nazi Holocaust have continued to suffer from depression, sleep disturbances, nightmares, chronic anxiety and a variety of somatic problems. Psychotherapeutic work with the survivors has been relatively ineffective primarily because some of these posttraumatic patients were unable to access their harmful experiences. Denial, repression and dissociation are among the commonly employed defense mechanisms that prevent adequate processing and subsequent integration of their atrocious pasts. The treatment of chronic and complicated post-traumatic-stress-disorder (PTSD) is a challenging and demanding undertaking for both patient and therapist and frequently requires emotionally strenuous uncovering. The now aging Holocaust survivors may be put at risk if affectively intense abreactive treatments are employed. This chapter concerns itself with advisable precautions to be implemented if uncovering of repressed material with these often medically compromised patients is indicated. A gradual regulated hypnotherapeutic approach that safeguards the older patient from undue stress is described.

The psychological aftermath of Nazi persecution on Holocaust survivors has been studied and documented throughout the last half of the century (Chodoff, 1980, Eitinger and Strom, 1973, Eitinger, 1980, Hoppe, 1971, Niederland, 1964). Survivors who availed themselves of psychotherapy seemed to have continued to suffer from depression, a variety of somatic and pain disorders, sleep and dream disturbances and pervasive anxiety (Eitinger, 1980), as well as from personality disorders associated with chronic aggression (Hoppe, 1971), failed empathy (Laub \& Auerhahn, 1989), anhedonia and alexithymia (Krystal, 1978a, 1978b). Fifty years after World War II survivors need to adjust to the challenges of senescence as they continue to struggle with the debilitating effects of their harmful past experiences. The last phases of human development associated with old age involve the need to revise and evaluate one's life. With a diminishing future one is left with the challenge of renunciation. The need is to compare one's past life goals and aspirations with outcomes and achievements, to redefine one's 
being through the having been, to give meaning to past arbitrary inevitabilities, to accept failures and lost opportunities and to integrate embedded memories into peaceful acceptance. Retirement and aging frequently are associated with diminishing gratification, increased somatic discomfort, gradual loss of autonomy and the need to cope with death of friends and loved ones. These stressors can reactivate repressed past traumata and produce extraordinary psychological pain. Before I examine the special considerations in hypnotherapy with aged survivors of the Holocaust let me review some known outcomes of catastrophic psychic trauma.

\section{EMOTIONAL EFFECTS OF THE HOLOCAUST EXPERIENCE}

The surrender to the unavoidable danger, rather than the exposure to intense overwhelming stimuli, is the key variable in adult catastrophic trauma (Krystal, 1971). The process of leamed helplessness often led to automatic obedience through blocking of affective and pain reactions. The process has been termed by Lifton (1967) as a "psychic closing off." This emotional anaesthetic, a dissociative defence mechanism, was adaptive for survival in the concentration camps. The process, however, frequently has lasted long after the liberation, resulting in a continuation of cognitive constriction, helplessness, non-assertiveness and passivity. A perpetuation of the traumatic process is manifested in nightmares depicting a dreaded calamity, hypervigilance, expectational anxiety and displaced screen phobias related to threatening memories.

Another rarely resolved theme in the lives of survivors is related to what Primo Levi (1961), described as the experience of being "desperately and ferociously alone" (p. 80). The essence of the Holocaust experience is not only the inability to affect the interpersonal environment, but also what Laub and Auerhahn (1989) described as a massive failure of the interpersonal environment to mediate both basic physical needs as well as needs for empathy. The Nazis not only killed Jews but also managed first to destroy their victims' self image as humans. So radical and brutal was the Nazi negation of Jews that it severely debilitated their sense of mutuality, their hopes to be heard and their capacity to be aware of theirselves. 
This handicap helps survivors to avoid the overwhelming emotional burden associated with their memories.

According to the Dutch psychiatrist Bastiaans (1974), the survivors' capacity for control and repression eventually diminishes, possibly because of early aging symptoms they tend to develop as a result of the physical hardships of the camp (Eitinger, 1964). Israeli studies concerning adjustment of survivors found that they are more vulnerable to the stresses of life, they are more depressed and less optimistic (Dor-Shav, 1975). Others conclude that the chronic concentration camp syndrome has not been very responsive to psychotherapy (Dasberg, 1987, Krystal, 1991).

\section{PSYCHOTHERAPEUTIC ISSUES IN THE TREATMENT OF SURVIVORS}

\section{Obstacles}

One major inherent problem hinders the psychotherapeutic process with survivor patients. In response to the overwhelming experiences, victims have failed to master their vehement depression, anxiety and anger. They fragmented the experience and repressed its threatening components. Frequently, only traces of the original trauma avail themselves to conscious awareness. The ensuing affective, cognitive, behavioral and somatic disturbances associated with the intense unresolved experience become isolated and clinically unyielding symptoms. The resolution of the traumatic experience is rendered impossible because it is greatly unintegrated and therefore, frequently, unrecognized. If the narrative of the trauma with all its integrated experiencial modalities is unavailable to the patient, interpretative work would be futile.

In psychodynamic terms, severe trauma creates primary repression in which no trace of a registration of any kind is left in the psyche (Kingston and Cohen, 1986). While psychodynamic theory of coping with trauma deals with repression in relationship with internal personality functioning and unresolved early conflicts (Kardiner, 1941; Fenichel, 1945), Janet proposed dissociation and the idea of vertical splits in personality that bring about new cores 
of consciousness that store parts of the threatening experience, safely isolating them from conscious awareness (Van der Hart and Friedman, 1989). Thus, when a split exists between ego states, there is no guarantee that psychotherapeutic work done with one ego state will permeate to the others and affect them. Most survivors described at least moderate degrees of depersonalization and derealization upon exposure to the unbelievable reality of the Nazi terror (Bettelheim, 1960; Blum, 1948; Cohen, 1953; Levi, 1961). I suggest that severely and chronically traumatized victims have continued to use these once adaptive survival mechanisms. These processes later evolved into rigid dissociative defenses that prevent adequate healing in conventional psychotherapy.

\section{Overcoming Dissociation}

Back in the early 1960 s a few reports started to recognize the need to help some of the psychotherapeutically resistant survivors to relive their experiences. While Engel (1962), for example, believed such processes would also help "long repressed affects of defiance and counter-aggression" (p. 202), he advocated Narcoanalytic and hypnotic methods to help those patients resolve their traumatic experiences. Niederland (1964) advocated that the only way to help the psychologically debilitated survivors was to take them back in time and have them work through, against their enormous resistance, the traumatizing events. Although he had failed to specify the techniques he recommended to be used, Niederland did propose to "use the charged hypermnestic material appearing in their dreams and nightmares to overcome gaps of memory ... and to arrive via association and detailed exploration of the persecution events at the deeper layers of guilt, shame and fear connected with these experiences" (p. 473).

Hypnosis has been considered a method of choice in the treatment of dissociative disorders (Kingsbury, 1988). It is a process which actually facilitates dissociation between different cognitive systems and between physical and emotional sensations (Hilgard, 1970). The perspective of hypnosis as controlled dissociation renders it a useful tool in psychotherapy for posttraumatic disorders (Spiegel \& Cardena, 1990). There has been a renewed and growing interest in both the role of dissociation in various psychiatric disor- 
ders, as well as in the potential contribution of hypnosis in the treatment of these problems. One of the principles emerging from the study of the now more readily identified dissociative reactions is that, indeed, the vast majority of those disorders are traumatically induced (Putnam, 1985). When one systematically inquires about such experiences, dissociative phenomena such as out-of-body experiences, amnesia and profound detachment are commonly described by combat veterans (Ewalt \& Crawford, 1981). Strong evidence exists today, linking the development of the most extreme pathology of dissociation-multiple personality disorder (MPD) to severe, recurrent traumatic experiences usually occurring during childhood or early adolescence (Putnam, 1989). Several authors have suggested that similar processes and outcomes have been developed by survivors of sustained life-threatening experiences, such as intermment in a concentration camp (Frankenthal, 1969, Bettelheim, 1979). The etiological and clinical similarities that exist between survivors of Nazi persecution and survivors of prolonged child abuse enable us to borrow from the considerable MPD treatment experience accumulated thus far. An extensive discussion of the treatment of MPD and dissociative disorders available elsewhere (Braun, 1986; Putnam, 1989), is beyond scope of this article. The critical issue for this paper is that severe dissociative disorders though treatable, present for both patient and therapist an arduous task that almost involves strong affective experiences, vigorous abreactions and prolonged exposures to deeply unsettling and upsetting materials (Kluft, 1984).

Can the aging and often physically compromised survivors of the Nazi Holocaust withstand such an undertaking or will the methods that proved successful with less vulnerable younger survivors of prolonged traumata actually endanger our older patients?

\section{Hypnoanalytic Techniques}

Hypnotic abreaction has a long history. Janet (1925) Pioneered it in the 1870s, Freud and Breuer utilized it in the 1880s for the treatment of hysteria (1955). Abreaction assumes an hydraulic model of the personality. According to this model postraumatic symptoms are a consequence of repressed emotions. The goal of treatment is the recovery of amnestic material to facilitate free 
expression of pent-up emotions, to reconstruct memory and integrate the experience.

In his work with older survivors the therapist must give supreme priority to the first rule of Hippocrates: First do not harm. Treatment needs to employ progressive uncovering, working through and integration which enable the patient to gain a sense of cognitive and emotional control over the threatening repressed traumata, as well as adequate protection against retraumatization (Brende \& Benedict, 1980; Spiegel, 1981).

In his work with older MPD patients, Kluft (1988) insists on the patients having a personal physician with whom he could discuss the medical aspects of their capacity to tolerate extreme stress. Cardiovascular stress tests and 24-hour electrocardiogram monitoring are among the recommended preliminary diagnostic evaluations to be taken. To assess the patients' capacities for the uncovering, positive, symptom relief oriented hypnotic experiences are used first. This process enhances trust and bonding with the therapist. It also contributes to an optimistic expectation as far as treatment efficacy is concemed.

Survivors are sometimes able to ward off intrusion of traumatic experience into consciousness by suppressing hypnotic ability. Brown and Fromm (1986) have observed that posttraumatic stress disorder (PTSD) patients can initially appear to be poorly hypnotizable and quite agitated during induction. To avoid sudden emergence of intense affect or traumatic re-enactment they suggest to delay the use of hypnosis in favor of waking relaxing imagery and parallel interpretation of the resistance to hypnosis as possible posttraumatic defensive symptomatology. The chronic exposure to dehumanizing life-threatening circumstances had impaired normal affective development of many young victims and had precipitated a pathological formation of identity. Nevertheless, these patients seldom associate their psychological deficiencies and distress with the experience of their horrific past.

I frequently try to educate the patients about the nature of their problem and it's inevitable relationship with the difficult events of the war. Open discussion of the typical psychological manifestations of PTSD normalizes their abnormality. That is, it defines their symptoms as a normal reaction to an abnormal situation. This can 
not only further enhance the therapeutic bond but it also conveys messages of recognition and respect to a degraded pathological selfrepresentation often found among Holocaust survivors (Krystal, 1968). Horowitz (1973) asserted that a psycho-educational component in therapy can facilitate better cooperation with the cognitive/ affective processing of the trauma, necessary for recovery. If the patients are sufficiently educated and are not afflicted with any psychiatric organicity, I also tend to encourage them to read historical material concerning their plight, as well as literature on PTSD and the survivor syndrome. This could not only be a first waking state step in accessing repressed material, but it also provides a conceptual framework for their condition. During this first stabilization phase I attempt to determine the patients' capacity to utilize relaxation skills and ego-strengthening suggestions. I also try to evaluate their ability to reduce distress in the subsequent uncovering.

Based on these assessments I decide whether or not to move on. I next tend to utilize an intervention Bellak and Faithem (1981) termed "mediate catharsis." In this technique, also used by Kluft (1988) for the treatment of older survivors of incest, I guide the patients in waking imagery to known or suspected emotionally charged situations of the past for which the patient has either no specified recollection or no access to affect. To this guided imagery I add an emotional "soundtrack" by expressing the affect I suspect the patient felt. This process bypasses alexithymic numbing and may facilitate enrichment of the psychological experience. Another technique I use to help the patient associate the various components of the dissociated trauma experience is the "affect bridge" (Watkins, 1971). This method can only be utilized if any particular feeling is salient and is experienced with some intensity. It is of particular usefulness with patients who display dissociated and unyielding affective symptoms. The technique could be first tried with positive feelings such as happiness, but with anhedonic patients, sadness, anger or fear are frequently the only available emotions. The patient is asked to imagine that he is travelling along a bridge of emotion to a time earlier in his life when he felt exactly the same. This second phase of therapy gently attempts to perforate the anaesthetic repressive and amnestic barriers of the survivor. 
Hypnoprojective methods can also be used in the service of a preliminary uncovering approach. The "Cloud Fantasy," "Crystal Gazing," or the "Theatre Technique" (Brown \& Fromm, 1986) are alternative ways of allowing the survivors' unconscious mind to project scenes that are safely disguised yet cautiously revealing. To be able to proceed without risking maladaptive anxiety or depression states, one must be ready to help the patient enhance tolerance for the emerging or intensifying feelings. One of my favorite methods for attenuating affect in survivors is the "Safe Place" method, in which it is suggested that upon having given a signal the patient will find himself in a very comfortable and safe place. The patient is then asked to describe the safe place and is reminded that he can retum to it whenever he fears overwhelming emotions begin to come up. Encouraging the survivors to apply auto-relaxation and self-soothing methods is not only a relevant adjunct technique but also an important curative approach facilitating the symbolic formation of a healthier self-representation capable of internal empathy and nurturance.

A suggested means of controlling the abreactive phase is to have survivors utilize their own defenses as affect regulating mechanisms. The therapist can suggest that the patients operate an imaginary videotape via a remote control device that can both tum the channels as well as control the brightness and volume of the picture on the monitor. The dissociation of the experiencing ego (projected on the monitor) from the observing ego enables the elderly patient to modify the intensity of the emotional experience to tolerable levels.

Another variation on this idea is the "slow-leak" technique (Kluft, 1988). The therapist can suggest to the hypnotized patient that their toxic feelings and impressions cannot be contained forever and thus should be deliberately allowed to leak in minuscule droplets at a rate that would provide no risk to the survivor.

A third recommended precautionary technique to dilute the intensity of affect is to do frequent "fractionated abreactions" (Fine, 1991) rather then a full abreaction. This method helps the patient uncover the encapsulated trauma in small increments. In a desensitizing manner, feelings are slowly reconnected to discrete aspects of the newly uncovered history of the survivor. 
Finally, it is advised that each session in which hypnotic uncovering is achieved should be closed with a suggestion for posthypnotic amnesia. Such a message should suggest that the patient will remember only what he is ready to remember and that he will gradually come to reown all the events, feelings and meanings necessary for his healing.

\section{ILLUSTRATIVE CASE STUDY}

\section{Background}

Bronya is an Israeli woman, Holocaust survivor bom in Poland. She was 58 years old at the time of therapy. She has a son, a married daughter and three grandchildren. Bronya has a Master's degree in social-work, which she earned in her mid-fifties. Because she is married to an independently wealthy lawyer, she has preferred to volunteer her time, working on behalf of Jewish Ethiopian immigrants. She has performed this job as if it were a duty, appearing to be rather detached and intellectualizing with regard to her motives. Bronya, the sole survivor of her family, arrived in Israel in 1949 with a group of orphaned young survivors and was put up in a boarding school. She was one of the very few children who had survived Auschwitz. The patient was self-referred for hypnoanalysis and treatment of onset insomnia, fear of the dark, recurrent depressive symptoms and frequent episodes of explosive anger. Additionally, the patient suffered from high blood-pressure, irritable bowel syndrome, chronic headaches and arthritis. Two years prior to the beginning of this psychotherapy, the patient had suffered a mild myocardial infarction. She had been treated with betablockers and analgesics.

Although Bronya had some circumstantial explanations for her labile moods, she considered them to be both excessive and damaging. Previously, she had been in therapy with two psychoanalytically oriented psychotherapists, who helped her to better understand the relationship between her current anxiety and anger, and her experiences during World War II. Nevertheless, Bronya noticed only a slight change in the severity of her symptoms. After almost a 
year without psychotherapy, she decided to seek help again. Her last crisis followed an intensive anxiety reaction she suffered as a result of a traffic ticket given to her on Holocaust Memorial Day.

Bronya was eleven years old when she saw the American liberators enter the gates of Auschwitz. This ended a one year internment in the death camp, where her parents were annihilated. The patient's life was saved in Auschwitz by a non-Jewish female physician who adopted the child and had employed her in the camp's infirmary.

\section{Medical Preparation}

Bronya's physician was consulted with regard to her capacity to withstand the potential stress which traumatic repressed material might elicit if tapped. He encouraged us to proceed with hypnoanalysis, but advised against sudden exposures to extreme emotional arousal. The physician decided to prophylactically increase the dosage of her beta-blockers. Doses of Propranolol were raised to $240 \mathrm{mg}$ per day, which was given in 3 equal daily doses. As an additional protective measure, she was also put on $75 \mathrm{mg}$ per day of Oxazepan, a benzodiazepine, also administered in divided doses. For the duration of the hypnoanalytic intervention the patient was scheduled for weekly blood-pressure monitoring appointments with the clinic's nurse.

\section{Initial Assessment Phase}

During the first five sessions, the patient's life history was taken. She also completed the Hebrew version of the MMPI (Montag, 1977) and the Dissociative Experience Scale (DES) (Bernstein and Putnam, 1986). The diagnostic impression was one of post-traumatic-stress-disorder, chronic; with dissociative features and psychosomatic correlates. The patient was amnestic to almost the entire duration of her imprisonment in Auschwitz.

Fragmentary recall was devoid of any affect. The patient had only scarce memories of the years prior to her internment in the death camp. She felt as if her life began only following her liberation and subsequent immigration to Israel. 
Bronya was interested in trying hypnoanalysis and hypnotherapy in the hope of relieving what seemed to her as life-long suffering.

\section{Psychological Preparation}

In order to enhance bonding with the hypnotherapist, to assess Bronya's hypnotic abilities and to help her build both a sense of inner-safety and self-mastery, she was first taught autorelaxation and a few pain management skills to help her gain initial symptom relief. The patient demonstrated a capability to utilize imagery and cognitive-behavioral skills, and seemed to be encouraged by her newly discovered self-efficacy. She was later taught to create a mental "safe place" and was given practice in both accessing it, as well as enjoying herself in it. Her chosen image was one of drinking ice-coffee in a jacuzzi hot tub.

\section{Initial Exploration}

In our fifth psychotherapy session I started taking a very detailed history of the patient's life. She was the only child of a working class, religiously observant father and a protective, demanding, but warm mother, who had been a homemaker. Bronya was only five years old when the Germans invaded Poland and terminated her normal childhood. The patient was never sure whether her scant memories were products of her dreams and imagination or, rather, traces of her past reality. Her description of the persecutions, the deportations and the losses she endured, were vague and emotionally empty. Initial attempts to access the patient's affect was through a guided waking imagery, to which the patient had to imagine not only the described sights and sounds, but also the correspondent emotions.

For example: "You are getting ready to leave your home in Warsaw. You do not, really, know what is going on, but Mom and Dad seem, to be really worried. They tell you, you will all be coming back, but you can tell Mother is very upset. You are worried and scared. You don't want to go downstairs where the soldiers are angrily shouting words in a language you do not understand..."

Bronya responded well to such exploratory "emotional sound- 
tracing." Major known events from her childhood were fed-back to her in that fashion. The patient reported in the subsequent debriefings that although she could occasionally sympathize with the imagined "Bronya the girl," and feel sad for her, she had been observing these described events as an outside onlooker. She was obviously still dissociating from many of the related feelings. Interestingly, the patient had started reporting at that time a correspondent deterioration in her initial presenting symptoms, and expressed concern over the potential danger of this therapy. She was consequently given further explanations regarding the nature and treatment of post-traumatic dissociation. Bronya was also reinforced for her courage and was reassured that she was, indeed, making progress.

\section{Abreactive Exploration}

The utilization of hypnoanalytic techniques started on our 19th session. Bronya came in visibly upset. She reported bitter quarrels with her husband and inexplicable, intense anxiety that worsened at night. The symptomatic episode had apparently started a few hours after the following incident: in her line of duty as a volunteer social worker, she found herself helping a crying girl who was being separated from her father as he was being arrested for domestic violence.

Bronya was able to make the obvious rational connections between this incident and its emotional ramifications, and her own past. However, no associated traumatic memories were recalled. To lessen some of the anticipated affect, Bronya was asked first to go to her "safe place" and to relax in her imaginary hot tub. She had also been reminded that at any point in her hypnoanalysis, she might be given the suggestion to go to her "safe place" and that she would be able to follow the suggestion with complete enthrallment and relaxation. The patient was then put in a hypnotic trance and was asked to imagine a bridge of anger and fear, that began at the arrest scene she had recently witnessed, and spanned all the way to an earlier time when she had had similar emotions. She was then encouraged to walk on that bridge to its other end. As expected, Bronya found Auschwitz on the other side. She was in her father's arms, her mother standing close by. They had just got off the train. 
Guards were shouting, and their German Shepherds were barking viciously. A tall officer asked her parents some questions. Then her father had to go to a different line. The child cried for her father. Tears were rolling down Bronya's face as she was describing the last time she saw her father, her body started to tremor with anxiety. At that point, she was promptly asked to go back to her "safe place" and relax. Out of trance, we later discussed the relationship between the precipitating trigger event, her intense emotional reactions, and the original trauma.

In the following months, Bronya was seen twice a week. She started to share very rich dream material, that when elaborated and explored in hypnoanalysis with the "videotape technique," provided a wealth of repressed memories associated with scenes of witnessed Nazi cruelty, loneliness and fear.

\section{Post Abreactive Psychotherapy}

In the next phases of therapy, Bronya was supported through a period of genuine grief she had experienced over her murdered parents and her lost childhood. She was only later able to recognize the fear she had of expressing anger toward the Nazis. The rage against the perpetrators had been, eventually, accessed and reowned. The angry feelings were so intense, they had to be first released in an attenuated way, in a fractionated abreaction under hypnosis. In some of these sessions, the patient imagined herself returning to Auschwitz with the Israel Defence Forces, liberating the camp's inmates and bringing "little Bronya" back home with them to Israel.

The last phases of therapy focused on resolving Bronya's guilt over the pain and distress she had caused to her current family throughout the years. The treatment was terminated with several family therapy sessions, in which she shared with her loved ones, for the first time, the now accessable emotional testimony of her ordeals during the Holocaust.

\section{Epilogue}

Eighteen months after this treatment started, Bronya felt she was ready to terminate it. Although she was still uneasy in the dark and 
continued to avoid being alone at night, she was much calmer and considerably less angry. Physically, there was little improvement in her high blood-pressure. However, it seemed to be controlled with medication. Improvements were reported with regard to the frequency and intensity of her chronic headaches. Her irritable bowel symptoms appeared to have gone completely and at the end of therapy Bronya no longer suffered from sleep disturbance. However, years of marital conflict have taken their toll on the marriage. Her husband was emotionally alienated and showed no more sexual attraction to her. Even though the couple was uninterested in further marital therapy, they did continue to be committed to each other.

On a follow-up telephone interview, conducted half a year after the treatment had ended, Bronya reported she was still maintaining her gains. She also told me that her husband and she had just returned from a trip to Poland. Bronya had fulfilled an old wish to lay flowers in the gas chamber and near the ovens where her parents perished.

\section{DISCUSSION}

Krystal (1991) has argued that psychotherapeutic work with Holocaust survivors has been ineffective because they fear their emotions and because they suffer from profound repression which prevents recognition of their inner reality.

Uncovering and abreactions are necessary components in the treatment of survivors of prolonged traumatic stress. Their purpose is to educate, to achieve continuity of memory content and to release encapsulated traumatic affect.

Hypnosis can be a valuable tool in attaining these goals. Other survivors who have not fully benefited from past therapies, may gain from therapeutically active progressive attempts to recover, work through and reincorporate traumata of the past. Hypnosis can help the patient gain a sense of control over the potentially intrusive experiences, and thus, makes them more available for psychotherapeutic processing. The utilization of hypnosis can also provide the survivor with the emotionally corrective experience of the therapist's solidarity and empathy. The hypnotherapist who works 
with the complicated Holocaust PTSD patient must function as a benevolent self-object (Kohut, 1971), showing active care and support.

Time is running out on the now aging and rapidly dying survivors. Many of them have learned to tolerate high levels of distress and a compromised quality of life. The sense of haste is indeed sometimes ours, the therapists'. Allowing these victims to carry their testimony buried in their wounded souls and ailing bodies could, to my mind, amount to a symbolic victory for the perpetrators. The sense of obligation we feel towards these elderly survivors should, however, never be translated into pressure to engage in emotionally strenuous uncovering procedures. Patients are definitely to be encouraged to participate in the setting of their therapy goals but sometimes we need to over-rule ambitious strivings for any hypothetically ideal outcome in favour of concerns for the patients' safety. A cognitive behavioral model is a viable alternative for survivors who cannot engage in uncovering but may need to leam how to modify maladaptive cognitions, acquire assertiveness skills or learn voluntary control of autonomic hyperactivity. The therapeutic suggestions provided in this paper should be implemented with caution and regarded as preliminary. Unfortunately, systematic outcome research of hypnotherapeutic uncovering with Holocaust survivors has yet to be carried out. It is hoped that this paper will promote further interest in this area and that, subsequently, we will soon acquire a better knowledge concerning the best curative approaches for these surviving victims.

\section{REFERENCES}

Bastiaans, J. (1979). Het KZ-syndroom en de menselijke vrjheid. Nederlands Tijdschrift voor Geneeskunde, $118,1173-1178$.

Bellak, L. \& Faithom, P. (1981). Crises and special problems in psychoanalysis and psychotherapy. New York: Brunner/Mazel.

Bernstein. E.M. \& Putnam, F.W. (1986). Development, Reliability, and Validity of a Dissociation Scale. Journal of Nervous and Mental Disease, 174, 727-735.

Bettelheim, B. (1960). The informed heart. Glencoe, Dlinois: Free Press.

Bettelheim, B. (1979). Surviving and other essays. New York: Harcourt Brace Jovanovich.

Bluhm, H.O. (1948). How did they survive? American Journal of Psychotherapy, 2, 1-9. 
Braun, B.G. (ed.) (1986). Treatment of multiple personality disorder. Washington, DC: American Psychiatric Press.

Brende, J.O. \& Benedict, B.O. (1980). The Vietnam combat delayed stress syndrome: Hypnotherapy of "dissociative symptoms." American Journal of Clinical Hypnosis, 23, 34-40.

Breuer, J. \& Freud, S. (1955). Studies of hysteria. I: On physical mechanisms of hysterical phenomena: preliminary communication. In: J. Strachey (ed.), Standard Edition, 2, pp. 1-181. London: Hogarth Press (original work published 1893-95).

Brown, D.P. \& Fromm, E. (1988). Hypnotherapy and hypnoanalysis. Hillsdale, New Jersey: Lawrence Erlbaum Associates, Publishers.

Chodoff, P. (1980). Psychotherapy with the survivor. In: Dinsdale, J. (ed.). Survivors, victims and perpetrators. Washington: Hemisphere Publishers.

Cohen, E.A. (1953). Human behavior in the concentration camp. New York: Norton.

Dasberg, H. (1987). Psychological distress of Holocaust survivors and of fspring in Israel, forty years later: A review. Israel Journal of Psychiatry and Related Sciences, 24, 243.-256.

Dor-Shav, N.K. (1978). On the long-range effects of concentration camp internment on Nazi victims: 25 years later. Journal of Consulting and Clinical Psychology, 46, 1-11.

Eitinger, L. (1964). Concentration camps survivors in Norway and Israel. Oslo/ London: Oslo Universitets forbaget/Allen and Unwin.

Eitinger, L. \& Strom, A. (1973). Mortality and morbidity of excessive stress. New York: Jason Aronson.

Eitinger, L. (1980). The concentration camp syndrome and its late sequence. In: Dimsdale, J. (ed.). Sunvivors, victims and perpetrators. Washington: Hemisphere Publishers.

Engel, W.H. (1962). Reflections on the psychiatric consequences of persecution. American Journal of Psychotherapy, 16, 191-203.

Erickson, E.H. (1963). Childhood and society (2nd ed.). New York: Norton.

Erwalt, J.R. \& Crawford, D. (1981). Posttraumatic stress syndrome. Current Psychiatric Therapy, 20, 145-153.

Fenichel, P. (1945). The psychoanalytic theary of neurosis. New York: Norton.

Fine, C.G. (1991). Treatment stabilization and crisis prevention: pacing the therapy of the multiple personality disorder patient. Psychiatric Clinics of North America, 14, 661-675.

Frankenthal, K. (1969). Autohypnosis and other aids for survival in situations of extreme stress. International Journal of Clinical and Experimental Hypnosis, $17,153-159$.

Hilgard, J.R. (1970). Personality and hypnosis: A study of imaginative involvement. Chicago: The University of Chicago Press.

Hoppe, K.D. (1971a). The aftermath of Nazi persecution reflected in recent psychiatric literature. International Psychiatry Clinics, 8, 169-198. 
Hoppe, K.D. (1971b). Chronic reactive aggression in survivors of severe persecution. Comprehensive Psychiatry, 12, 230-236.

Horowitz, M.J. (1973). Phase oriented treatment of stress response syndromes. American Journal of Psychotherapy, 27, 506-515.

Janet, P. (1925). Psychological healing: a historical and clinical study (Eden Paul \& Cedar Paul, Trans.). New York: McMillan (originally published 1919).

Kardiner, A. (1941). The Traumatic Neurosis of War. New York: Paul Hoeber.

Kingsbury, S.J. (1988). Hypnosis in the treatment of posttraumatic stress disorder. An isomorphic intervention. American Journal of Clinical Hypnosis, 31, 81-90.

Kingston, W., Cohen, J. (1986). Primal repression: clinical and theoretical aspects. International Journal of Psychoanalysis, 67, 337-356.

Kluft, R.P. (1984). Aspects of the treatment of multiple personality disorder. Psychiatric annals, 14, 51-55.

Kluft, R.P. (1988). On treating the older patient with multiple personality disorder: "Race against time," or "Make haste slowly?" American Journal of Clinical Hypnosis, 30, 257-267.

Kohut, H. (1971). The analysis of the self. New York: International Universities Press.

Krystal, H. (ed.) (1968). Massive psychic trauma. New York: International Universities Press.

Krystal, H. (1971): Trauma: consideration of severity and chronicity. In: H. Krystal and W. Niederland (eds.), Psychic Traumatization. Boston: Little, Brown \& Co.

Krystal, H. (1978a). Trauma and affects. Psychoanalytic Study of the Child, 33, 81-116.

Krystal, H. (1978b). Self representation and the capacity for self-care. In: The Annual of Psychoanalysis, VI, 209-246.

Krystal, H. (1991). Integration and self-healing in posttraumatic states: A ten year retrospective. American Imago, 48, 93-118.

Laub, D. \& Auerhahn, N.C. (1989). Failed empathy-a central theme in the survivors' Holocaust experience. Psychoanalytic Psychology, 6, 377-400.

Levi, P. (1961). Survival in Auschwitz. New York: Collier.

Lifton, R.J. (1967). Death in life: Survivors of Hiroshima. New York: Random House.

Montag, I. The Tel-Aviv MMPI: Some Validation Studies. Paper presented at the University of Haifa symposium on personality tests, Haifa, May 1977.

Niederland, W. (1967). Psychiatric disorders among persecution victims. Journal of Mental and Nervous Diseases, 139, 450-476.

Putnam. F.W. (1985). Dissociation as a response to extreme trauma. In Kluft, R.P. (Ed.). The childhood antecedents of multiple personality. Washington, DC: American Psychiatric Press.

Putnam. F.W. (1989). Diagnosis and treatment of multiple personality disorder. New York: The Guilford Press. 
Spiegel, D. (1981). Vietnam grief work using hypnosis. American Journal of Clinical Hypnosis, 23, 239-247.

Spiegel, D. \& Cardena, E. (1990). New uses of hypnosis in the treatment of posttraumatic stress disorder. Journal of Clinical Psychiatry, 51, 39-43.

Van der Hart, O. \& Friedman, B. (1989). A reader's guide to Pierre Janet on dissociation: a neglected intellectual heritage. Dissociation, 2, 3-16.

Watkings, J.G. (1971). The affect bridge: A hypnoanalytic technique. International Journal of Abnormal and Social Psychology, 42, 256-259. 